\title{
Artificial Intelligence in Workplaces and How It Will Affect Employment in Latvia
}

\author{
Ilmārs Šukjurovs \\ $M B A$ \\ Author "Turība" University \\ Riga, Latvia \\ ilmars.sukjurovs@gmail.com
}

\author{
Rosita Zvirgzdin̦a \\ Dr. oec. asoc. prof. \\ Supervisor "Turība" University \\ Riga, Latvia \\ rosita@turiba.lv
}

\author{
Silva Jeromanova-Maura \\ $M B A$ \\ Co. author Turība" University \\ Riga, Latvia \\ silva.jeromanova-maura@silja.biz
}

\begin{abstract}
Already, artificial intelligence (AI) is all around us, from self-driving cars and drones to virtual assistants and software that translate or invest. Impressive progress has been made in $\mathrm{AI}$ in recent years, driven by exponential increases in computing power and by the availability of vast amounts of data, from software used to discover new drugs to algorithms used to predict our cultural interests. Digital fabrication technologies, meanwhile, are interacting with the biological world on a daily basis. Engineers, designers, and architects are combining computational design, additive manufacturing, materials engineering, and synthetic biology to pioneer a symbiosis between microorganisms, our bodies, the products we consume, and even the buildings we inhabit. Companies in the technology, media, and telecommunications industry expect AI to have a significant impact on product offerings in the next five years. This research contains the data from a pilot survey from Latvian business executives' expectations for AI and robotics for the next 5 years. The aim of this research is to find out if AI and robotics will make significant impact on workplaces in Latvia in the next five years.
\end{abstract}

Keywords-artificial intelligence in business, economic theory, employment, Latvia.

\section{INTRODUCTION}

Modern information technologies and the advent of machines powered by artificial intelligence (AI) have already strongly influenced the world of work in the $21 \mathrm{st}$ century. Computers, algorithms and software simplify everyday tasks, and it is impossible to imagine how most of our life could be managed without them. However, is it also impossible to imagine how most process steps could be managed without human force? The information economy characterised by an exponential growth replaces the mass production industry based on economy of scales [1]. The so-called fourth industrial revolution is about to kick in. And it will happen at an exponential pace. Klaus Schwab wrote an article in the World Economic Forum what the fourth industrial revolution is. The First Industrial Revolution used water and steam power to mechanize production. The Second used electric power to create mass production. The Third used electronics and information technology to automate production. Now the Fourth Industrial Revolution is building on the Third one, the digital revolution that has been occurring since the middle of the last century. It is characterized by a fusion of technologies that is blurring the lines between the physical, digital, and biological spheres. There are three reasons why today's transformations represent not merely a prolongation of the Third Industrial Revolution but rather the arrival of the Fourth and distinct one: velocity, scope, and systems impact. The speed of the current breakthroughs has no historical precedent. When compared with the previous industrial revolutions, the Fourth is evolving at an exponential rather than a linear pace. Moreover, it is disrupting almost every industry in every country. And the breadth and depth of these changes herald the transformation of entire systems of production, management, and governance [2].

Expectations for artificial intelligence (AI) are skyhigh, but what are companies actually doing now? The gap between the ambition and execution is large at most companies. Three-quarters of executives believe AI will enable their companies to move into new businesses. Almost $85 \%$ believe AI will allow their companies to obtain or sustain a competitive advantage. But only about one in five companies has incorporated AI in some offerings or processes. Less than $39 \%$ of all companies have an AI strategy in place. The largest companies those with at least 100,000 employees — are the most likely ones to have an AI strategy, but only a half has one [1].

Countries with high labour costs are more likely to implement AI into their daily tasks, but how about Latvia? There is a pilot survey being conducted right now to find out what business executives in Latvia think about $\mathrm{AI}$ in their companies, what their expectations are, how informed they are about the AI opportunities, and how they value the AI possibility to replace low qualified employees.

\section{Materials AND METHOdS Theoretical Framework}

The name behind the idea of AI is John McCarthy, who began research on the given subject in 1955 and assumed that each aspect of learning and other domains 
of intelligence can be described so precisely that they can be simulated by a machine [3]. Artificial Intelligence is a broad spectre computer science, and it could use some classifications and definitions to set apart its fields of science. Till this day there are no types of AI that would be multi-purpose programs. AI is a single purpose only one that can play chess, cannot drive a car etc. However, Google DeepMind technologies are on its way to general purpose AI.

Artificial intelligence describes the work processes of machines that would require intelligence if performed by humans. The term 'artificial intelligence' thus means 'investigating intelligent problem-solving behaviour and creating intelligent computer systems' [4].

There are two kinds of artificial [5].:

1. Weak artificial intelligence: The computer is merely an instrument for investigating cognitive processes - the computer simulates intelligence.

2. Strong artificial intelligence: The processes in the computer are intellectual, self-learning processes. Computers can 'understand' by means of the right software/programming and are able to optimise their own behaviour on the basis of their former behaviour and their experience. (Shultz, 2016) This includes blockchain which is automatic networking with other servers or machines, and it leads to a huge scaling effect.

In general, the economic use of AI can be separated into six categories [5].:

1. Automation: What makes a system or process function automatically. For example, robotic process automation (RPA) can be programmed to perform highvolume, repeatable tasks that humans normally performed. RPA is different from IT automation in that it can adapt to changing circumstances.

2. Machine learning: The science of getting a computer to act without programming. Deep learning is a subset of machine learning that, in very simple terms, can be thought of as the automation of predictive analytics. There are three types of machine learning algorithms:

a. Supervised learning: Data sets are labelled so that patterns can be detected and used to label new data sets

b. Unsupervised learning: Data sets aren't labelled and are sorted according to similarities or differences

c. Reinforcement learning: Data sets aren't labelled but, after performing an action or several actions, the AI system is given feedback

3. Machine vision: The science of allowing computers to see. This technology captures and analyses visual information using a camera, analogue-to-digital conversion and digital signal processing. It is often compared to human eyesight, but machine vision isn't bound by biology and can be programmed to see through walls, for example. It is used in a range of applications from signature identification to medical image analysis. Computer vision, which is focused on machine-based image processing, is often conflated with machine vision.

4. Natural language processing (NLP): The processing of human -- and not computer -- language by a computer program. One of the older and best-known examples of NLP is spam detection, which looks at the subject line and the text of an email and decides if it's junk. Current approaches to NLP are based on machine learning. NLP tasks include text translation, sentiment analysis and speech recognition.

5. Robotics: A field of engineering focused on the design and manufacturing of robots. Robots are often used to perform tasks that are difficult for humans to perform or perform consistently. They are used in assembly lines for car production or by NASA to move large objects in space. Researchers are also using machine learning to build robots that can interact in social settings.

6. Self-driving cars: These use a combination of computer vision, image recognition and deep learning to build automated skill at piloting a vehicle while staying in a given lane and avoiding unexpected obstructions, such as pedestrians.

Dematerialisation. Thanks to automatic data recording and data processing, traditional 'backoffice' activities are no longer in demand. Autonomous software will collect necessary information and send it to the employee who needs it [4]. Additionally, dematerialisation leads to the phenomenon that traditional physical products are becoming software, for example, CDs or DVDs are being replaced by streaming services. The replacement of traditional event tickets, travel tickets or hard cash will be the next steps, due to the enhanced possibility of contactless payment by smartphone. And that is already happening, a large majority of Latvian people does not print event or plane tickets, even cash is used more rarely. Sweden even has a plan to be cash less country and now there is only $1 \%$ of Swedish citizens that use coins or money bills [6]. Gig economy. A rise in self-employment is typical for the new generation of employees. The gig economy is usually understood to include chiefly two forms of work: 'crowdworking' and 'work on-demand via apps' organised networking platforms [7]. There are more and more independent contractors for individual tasks that companies advertise on online platforms (eg, 'Amazon Mechanical Turk'). Traditional employment relationships are becoming less common. Many workers are performing different jobs for different clients.

These AI categories are most likely to reshape businesses as we know it in the next five years. There are a lot of workplaces that are under threat because of the rapid evolvment of AI. Robotics and AI could be a giant leap for the mankind and the old saying about janitor "Someone has to do that work too" will no longer apply to those lazy kids at school and low qualified workforce. People are meant to do more and be more. These monotonous and "dirty works" are the biggest time thieves in the $21 \mathrm{st}$ century. Of course, some people will loose their jobs 
in the next years, but who will be the first winners by implementing AI and robotics?

The winners of the digital revolution are highly developed Asian countries with good education systems, such as Singapore, Hong Kong, Taiwan and South Korea [8]. These countries - together with the Scandinavian countries - have been undertaking research and working to find digital solutions for complex issues for a long time. The digital interconnection of people in these countries is also very far advanced. The share of the population at risk of unemployment is about six per cent in these countries. Finally, Western developed countries will profit from the relocation of the companies' production sectors when robotic production becomes cheaper than human production in low-labour-cost countries. This will create new jobs in these countries and destroy many routine jobs in the low-labour-cost countries. Another positive trend can be seen for India and China, which are both considered very suitable candidates for participation in the digital revolution due to the most of the population having a good command of English and IT skills. IT knowledge is taught in schools as a key qualification. It is, therefore, not surprising that Indian and Chinese professionals have more extensive computer knowledge than their French or English colleagues do [9].

Not only are salaries and wages lower in India, but also the number of better qualified professionals is, that is why, according to Forrester Research, 25,000 IT jobs are likely to be outsourced to India from the UK alone [10]. The countries like China, India are in the process of developing from simply being a low-labour-cost country into being a Western-orientated society whose population works mainly in the tertiary sector. As the most populated countries in the world, these two countries have a high level of consumer demand. Moreover, because of their rapidly growing cities, these developing countries need highly developed solutions in terms of logistics and environmental technologies, like the smart city, in order to increase the quality of life for city residents over the long term. The digital world market leaders are based in Silicon Valley, California. In 2015, the top ten Silicon Valley startups created an annual turnover of approximately US\$ 600bn with information and communication services [11].

Additionally, the eight leading digital platforms - Alphabet, Amazon, Facebook, etc - due to their exponential growth show a significantly higher capital market value than the leading industrial companies (eg, General Electric, Siemens or Honeywell [12]. The rise of $\mathrm{AI}$ in the service sector, especially the gig-economy, can be illustrated by the example of Uber, which saw an increase in its market value from zero to US\$ 40bn in only six years [11]. Even though more than 80 percent of the robots sold each year are deployed in Japan, South Korea, the US and Germany and enhance productivity in the production sector, the new business models in the service sector are the digital future. With economic growth in this sector, the US will be particularly resistant to future economic crises. It is therefore not surprising that innovative countries like Switzerland, Germany, the US or Japan are rated best in the Global Competitiveness Index by the World Economic Forum [13]. In summary, it can be said that the increase of automation and digitalisation is a global concern that, due to the lack of financial possibilities in many developing countries, will initially be strongly focused on Western developed countries and Southeast Asia. These countries will be considered the winners of Industry 4.0 because of their technological head start and their creative service models. Owing to the great number of emerging multidisciplinary support alternatives due to $\mathrm{AI}$ and machines, the requirements for future employees will change. There will be hardly any need for employees who do simple and/or repetitive work. Already today, the number of factory workers is constantly decreasing, and humans are ever more becoming the control mechanism of the machine. The automotive industry, where many production steps are already fully automated, is the pioneer in this respect. The lower the demand for workers, the higher the companies' demand for highly qualified employees will be. According to a common belief, better education helps [14].

Better education helps, however, only in certain circumstances. An additional qualification of an individual employee must be connected to the work in question. Additional qualifications as an accountant will be of little benefit for an individual employee, because - over time - there is a 98 per cent probability that the work of an accountant can be done by intelligent software [15]

Creative people who are talented in mathematics and sciences are best qualified for the new labour market. Although not every future employee will be required to be an IT programmer, should have a fundamental grasp of analytical and technical matters. Employees should be able to form a unit with supporting machines and algorithms and navigate the internet comfortably and move safely in social networks. To do this, it is necessary to know how the basic structures work. The employee should also, however, be able to examine machines and software critically. There is an increasing demand for employees who can work in strategic and complex areas as well. It is not necessary only to oversee machines, but also coordinate them. The interfaces between humans and machines and the overlaps in the area of responsibility among the more flexible humans must also be coordinated. There is thus likewise an increasing demand for future executive staff with social and interdisciplinary competence [16].

Employees must be able not only to communicate with other people, but also, if necessary, lead them effectively and coordinate them. In addition, creativity and flexibility are becoming increasingly important. In the future, critical and problem-orientated thinking will be expected of employees as the most important requirement. This requires sound judgment. The expectations with respect to availability will be higher for future employees. Flexible working hours and standby duties will be the rule and no longer an exception in the labour market. Employees will be required to focus not only on one main practice area, but also take on several multifaceted, sometimes highly complex tasks as necessary, and also perform as part of 
a team. Employees are increasingly expected to have non-formal qualifications. These include, for example, the ability to act independently, build networks, organise themselves and their teams with a focus on targets, and think abstractly. Special knowledge or a flair for highquality craftsmanship will become less important, since this work is likely to be done by intelligent software or a machine. Mere knowledge workers will no longer be required; the focus will rather be on how to find creative solutions to problems [17].

Deals will still be made between people in the future, even if the facts may be gathered beforehand by software [18].

\section{Methods}

Using data from author survey, where 51 of Latvian business executives were surveyed. Business executives shared they predictions and opinions about impact on their businesses. The aim of this research is to find out if AI and robotics will make significant impact on workplaces in Latvia in the next five years.

\section{Results AND Discussion,}

Preliminary results of the pilot survey show a little insight of attitude and opinions about AI and robotics in business among the Latvian business executives. One of the questions is - how business executives in Latvia predict the impact on daily business tasks. The impact must be measured on the Likert scale from 1 (no impact) till 5 (huge impact). (See Figure 1.)

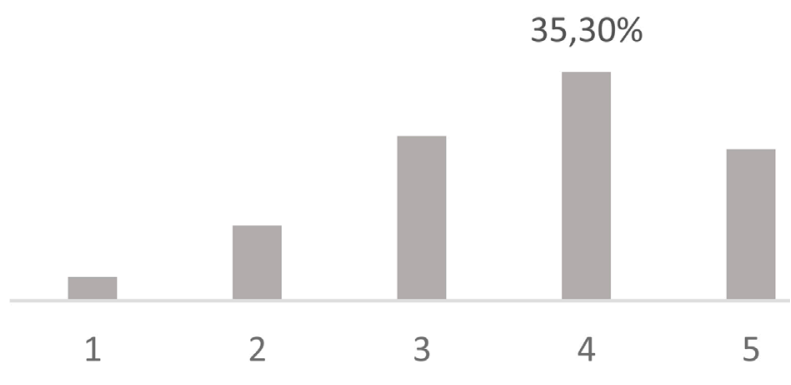

Figure 1. How you predict AI impact on your business in next 5 years?

More than a half of respondents notes that AI will have an impact on their businesses in the next five years, but a quarter of respondents notes that AI will have a moderate impact on their businesses in the next five years. Only approximately 16 percent of respondents note that AI will have no or little impact on their day to day business tasks.

One of the most interesting tasks in this ongoing survey is - how you rate your awareness about AI and robotics and its opportunities in business, on the scale from 1 (unaware) till 5 (fully aware). (See Figure 2.)

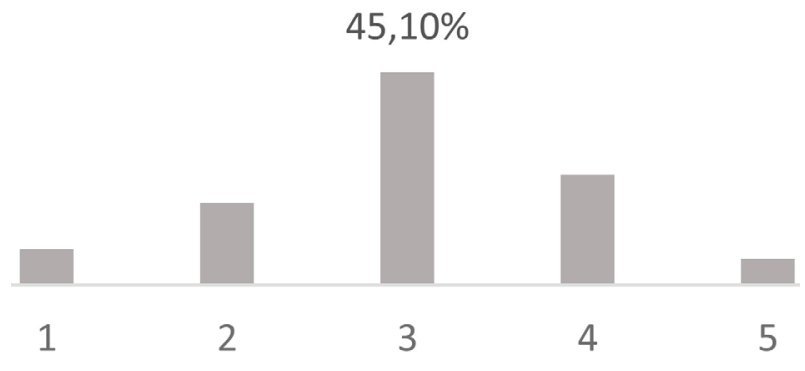

Figure 2. How aware you are about AI and robotics opportunities provided for your business?

It turns out that the majority of respondents are just partly aware about AI and robotics and their capabilities to implement their businesses. These results raise a serious question - if this survey reflects a real view on the next five years in AI impact on businesses since business executives are so moderately aware of AI and robotics opportunities provided.

As most technologically advanced countries are about to make changes in labour market thanks to AI and robotics, this matter should be next one to be rated among the Latvian business executives. Latvian business executives rate the possibility that some of workplaces could be replaced with AI and robots from 1 (low/ no possibility) to 5 (high possibility) (See Figure 3.)

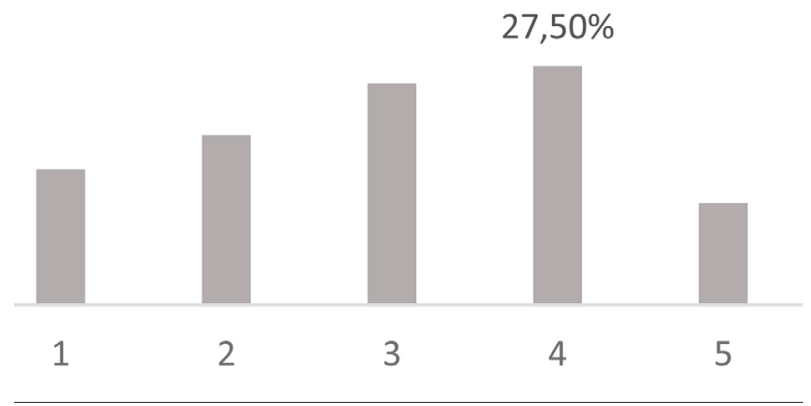

Figure 3. How you rate possibility to replace some workplaces in your business with AI or robots?

Approximately a third part of respondents believe that there is a big possibility that they will replace some human workers with AI or robots in the next five years.

There are many economic reasons businesses would like to adapt AI and robots in workplaces. But still there are people in businesses and always it's all about people. Respondents were asked - how do you value human interaction in daily problem-solving/tasks? Rating 1 (not necessary) till 5 (Highly necessary). (See Figure 4.)

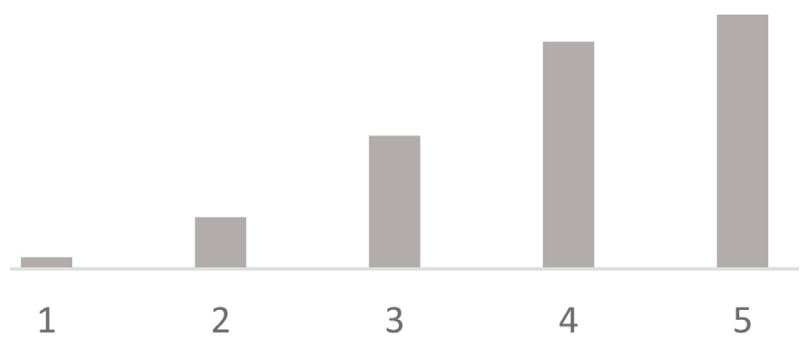

Figure 4. How do you value human interaction in daily problemsolving/tasks? 
Human to human interaction is highly necessary as the largest majority of respondents noted. Humans will work for humans for a long time for sure, but AI and machines could serve more and more humans in the coming years. Humans make mistakes more often than machines and can do tasks with high precision. In this survey executives rated - how they value execution of tasks with no human errors. Rating from 1 (unimportant) till 5 (very important). (See Figure 5.)

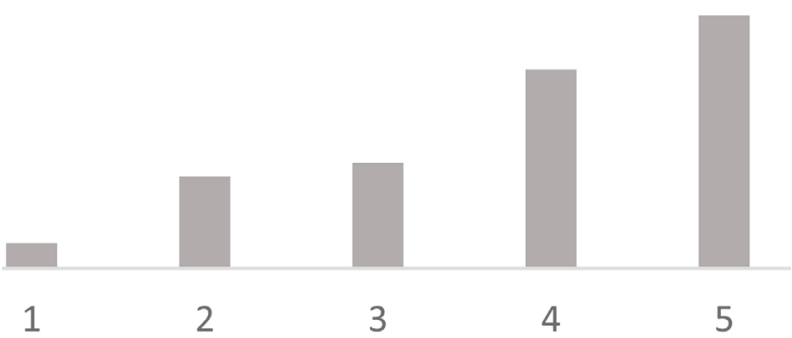

Figure 5. How do you value AI capability to do tasks without human errors?

The largest majority of respondents notes that a possibility to perform tasks without human errors is highly valued. Especially autonomous driving could save many human lives, because most of the fatal accidents are because of human errors, inattention and fatigue. Whereas, AI can operate $24 / 7$ with no loss of performance quality.

Author recommends Latvian business executives to learn more about AI - its` applications for business. As survey shows - respondents are moderately aware of AI and robotics and its' capabilities. Author presumes that if Latvian business executives learn more about AI and robotics, that the overall predicted impact un business and use of AI and robotics in workplaces could be more optimistic.

\section{CONClusions}

1. More than half of Latvian business executives predicts large and very large impact on their businesses in relation with AI and robotics progress. The indicators could be higher if Latvian business executives would be more aware of opportunities that AI and robotics offer.

2. Most of respondents worldwide see more opportunities than risks from $\mathrm{AI}$ and robotics.

3. Some legislation should be developed, approved regarding $\mathrm{AI}$ and robotics. The main reasons - who will take responsibility for mistakes and malfunctions (owner or manufacturer), in events where there are risks and damages done by AI, who would take the responsibility.

4. Author assumes that first automated jobs in Latvia will be for those positions, which not include working with people and tasks that requires precision with no human errors.

\section{REFERENCES}

[1]. Boston Consulting Group. (2017). Reshaping Business with Artificial Intelligence. MIT Sloan Management Review.

[2]. Schwab, K. (2016, 1 14). The Fourth Industrial Revolution: what it means, how to respond. Retrieved from World Economic Forum: https://www.weforum.org/agenda/2016/01/the-fourthindustrial-revolution-what-it-means-and-how-to-respond/

[3]. Tava, J. M. (2016, 2 11). Computer cloud is dead. Retrieved from Der Spiegel: http://www.spiegel.de/netzwelt/web/johnmccarthy-der-vater-der-rechner-cloud-ist-tot-a-793795 htm

[4]. Richard Lackes, Markus Siepermann. (2016, 2 11). Artificial Intelligence. Retrieved from Gabler: https://wirtschaftslexikon. gabler.de/definition/kuenstliche-intelligenz-ki-40285/ version-184779

[5]. Rouse, M. (2018). AI (artificial intelligence). techtarget. com:https://searchenterpriseai.techtarget.com/definition/AIArtificial-Intelligence

[6]. Savage, M. (2017). Why Sweden is close to becoming a cashless economy. http://www.bbc.com/news/business-41095004

[7]. Stefano, V. D. $(2016,926)$. The rise of the «just-in-time workforce»: On-demand work, crowdwork and labour protection in the «gig-economy». International Labour Office.

[8]. Widmann, A. (2016, 2 1). Tricks are the new B.R.I.C. Retrieved from Sueddeutsche Zeitung: http://www.sueddeutsche. de/wirtschaft/schwellenlaender-ticks-sind-die-neuenbrics-1.2844010

[9]. Sikka, V. (2016, 2 18). Amplyfing Human Potential. Retrieved from Experience Infosys: http://www.experienceinfosys.com/ humanpotential-infographic

[10]. Gatterer, H. (2013, 5 13). The reinvention of the working world. Retrieved from Zukunfts Institut: http://www.zukunftsinstitut. de/artikel/die-neuerfindung-der-arbeitswelt/

[11]. Kollmann, T. (2015). Digital Leadership. Bundestag, 18.

[12]. Roland Berger GmbH. (2016). Fair play in the digital arena. 90.

[13]. World Economic Forum. (2018, 22). Competitiveness Rankings. Retrieved from World Economic Forum: http://reports. weforum.org/global-competitiveness-report-2015-2016/ competitiveness-rankings/

[14]. Shultz, S. (2016, 08 3). Future of labour market. Retrieved from Der Spiegel: http://www.spiegel.de/wirtschaft/soziales/ arbeitsmarkt-der-zukunft-die-jobfresser-kommen-a-1105032. html

[15]. Klinge, \& Schmitd. (2016). Kolege roboter. Focus Magazin, 66.

[16]. Bochum. (2017). 'Gewerkschaftliche Positionen in Bezug auf "Industrie 4.0"'. Zukunft der Arbeit in Industrie 4.0, 36.

[17]. Zukunfts Institut. (2012). The reinvention of the working world. Retrieved from Zukunfts Institut: http://www.zukunftsinstitut. de/artikel/die-neuerfindung-der-arbeitswelt/

[18]. Anderson, J. Q. (2015). The Future of Work? The Robot Takeover is Already Here! Medium. 